\title{
S+ (1) Câu hỏi lơ lửng 10 năm
}

\author{
Vương Quân Hoàng \\ Phenikaa University
}

Hà Nội, Dec. 6, 2021

Cuộc đời này có rất nhiều sự tình cờ. Tuy vậy, có nhiều sự kiện tình cờ xảy ra không hoàn toàn ngẫu nhiên, mà cần những điều kiện nhất định được đáp ứng. Một loại tình cờ như thế có giá trị tiềm tàng rất lớn trong đời sống con người, được biết đến qua tên gọi "serendipity".

Nói cho đúng ra thì ngày nay đã có rất nhiều sách và tài liệu khoa học bàn về serendipity.

Bài viết này là sự khởi đầu một dự án của tôi khi chờ bước vào giai đoạn U6o. Và thực chất dự án này đã bắt đầu từ rất lâu. Thời gian gần nhất để đánh dấu nó là 10 năm trước, vào năm 2011.

Có thể nói, công việc này khá điển hình cho cái mà gần đây được đề xướng và đang trỗi dậy, gọi là slow science movement $[1,2]$.

Cách đây chừng 10 năm, Nancy K. Napier và tôi bắt tay vào triển khai một nghiên cứu thuộc thể loại lý thuyết đóng góp phát triển khuôn khổ nhận thức, thường được định danh thể loại conceptual development. Mãi tới 2013, nghiên cứu này mới được xuất bản dưới dạng một chương sách [3].

Mặc dù về cơ bản nghiên cứu này được coi là đóng góp thành công, thông qua đánh giá của đồng nghiệp và việc các tác giả sau này tiếp nhận và ứng dụng nó, nhưng bản thân tôi có một câu hỏi rất lớn về serendipity. Căn nguyên câu hỏi ấy như sau.

Bản chất của serendipity vẫn khá trừu tượng. Ngay trong tiếng Anh, từ serendipity cũng ít khi được dùng. Và trong quá trình sử dụng, các từ điển đồng nghĩa thường hay coi nói là tương đương với những khái niệm như luck, fate, đại loại là ám chỉ sự "may mắn". Mà may mắn thì như chúng ta vần hiểu hàng ngày là thứ gì đó nằm ngoài sự kiểm soát, hoạch định hay thậm chí khả năng nhận biết, nắm bắt của con người.

Rất tiếc, đó không phải là loại serendipity như tôi suy nghĩ, và như các tổ chức xã hội cách tiếp cận tri thức chúng ta cần. Chúng ta cần thứ có thể hiểu được, định nghĩa được, tiếp cận được, ứng dụng được, và phát triển các công cụ khai thác được.

Ngay từ đầu, dù cách hiểu có khác nhau đôi chỗ, nhưng cả Nancy và tôi đều đã hình dung về serendipity như một sức mạnh, công cụ có giá trị trong quá trình hoạch định và tổ chức chiến lược của con người. Sở dĩ có quan niệm này, là vì mối quan tâm trực tiếp lúc đó tập trung vào vận hành tổ chức kinh doanh, quản trị chiến lược. Vì thế ban đầu tiêu đề bài là "Serendipity as a competitive advantage" và sau đó được điều chỉnh khái quát hơn thành "Serendipity as a strategic advantage?". 
Tuy vậy, chẳng bao lâu sau tôi nhận thấy giới hạn của nghiên cứu này. Đó là giống như rất nhiều nghiên cứu khác thiên về "làm sao để khai thác tốt tài nguyên", nó vẫn không trả lời được những thắc mắc về bản chất, cội nguồn và cơ chế hình thành. Đây là một giới hạn chết người, vì nó chặn đứng khả năng đào sâu hơn nữa về cơ chế ứng dụng hữu ích, về công cụ nhận biết, và về hướng phát triển lý thuyết hữu ích rộng rãi trong hoạt động xã hội, tổ chức công việc của con người (trong đó có doanh nghiệp).

Câu hỏi này không phải là đợi tới khi nghiên cứu [3] ra đời và phản ánh qua việc sử dụng trong nghiên cứu, đào tạo mới xuất hiện. Mà thực ra nó đã xuất hiện từ trước cả khi đặt bút viết xuống những dòng đầu tiên của bản thảo. Nhưng với ưu tiên lúc đó, và khuôn khổ một bài nghiên cứu sẽ chỉ khoảng 20 trang, thì nó không được ưu tiên trả lời.

Vì thế, câu hỏi đó cứ treo lơ lửng hơn 10 năm qua. Và mặc dù sau này bận rộn với nhiều công việc nghiên cứu khác, nó chẳng hề biến mất, mà cứ lớn dần lên. Tại sao lại có chuyện bận việc, trong khi bài [3] đã hoàn thành và đạt mức độ hữu ích nhận biết rõ, mà câu hỏi lại cứ lớn lên, không biến mất?

Đó là vì bản thân tôi hết lần này tới lần khác được "hưởng" lợi ích của serendipity, và các dấu hiệu của serendipity thì rõ tới mức độ không thể chối cãi. Giá trị có tính chiến lược của nó cũng không thể chối bỏ. Và việc trả lời câu hỏi hóc búa về ý niệm và cơ chế của nó (hay gọi trong tiếng Anh là the nuts and bolts) trở thành thứ ngày càng đáng suy nghĩ, và rồi là một đáp án còn đang nợ. Món nợ tự mình nhận.

Ngoài ra, cũng chính vì việc tận dụng giá trị chiến lược này đạt hiệu quả nhiều lần, và đều được ghi lại dấu vết trong các ấn phẩm xuất bản, khả năng để truy xét dấu vết, liên kết bản chất và tìm về các yếu tô giấu mặt tác động lên quá trình xuất hiện năng lực serendipity cũng từ từ tăng trưởng [4,5].

Đến nay, do cơ bản đã có câu trả lời đáp ứng được mong ước của bản thân, tôi sẽ dành những ngày còn lại trước ngưỡng của U6o để viết xuống câu trả lời tìm kiếm ít nhất trong 10 năm qua. Câu trả lời sẽ khá bất ngờ với nhiều người, ngay cả trong giới nghiên cứu học thuật về quản trị và tâm lý. Câu trả lời này cũng chỉ có thể xuất hiện nhờ việc ứng dụng triệt để hai lý thuyết đặc hữu là mindsponge và $3 D$ creativity processes $[6,7]$.

(Cũng xin nói thêm là bản thân sự ra đời của hai lý thuyết nêu trên cũng có dấu ấn đậm nét của serendipity.)

Tôi xin cảm ơn những học trò đồng hành giúp tôi dần hình thành nên câu trả lời tại thời điểm nó xuất hiện, Lê Tâm Trí và Nguyễn Minh Hoàng.

\section{References:}

[1] Alleva, L. (2006). Taking time to savour the rewards of slow science. Nature, 443(7109), 271-271.

[2] Stengers, I. (2018). Another science is possible: A manifesto for slow science. John Wiley \& Sons.

[3] Napier, N. K., \& Vuong, Q. H. (2013). Serendipity as a strategic advantage?. In: 
T. Wilkinson (ed.) Strategic Management in the 21st Century (pp. 175-199). Praeger.

[4] Vuong, Q. H. (2021). The semiconducting principle of monetary and environmental values exchange. Economics and Business Letters, 9(3), 284-290.

[5] Vuong, Q.-H. (2021). Western monopoly of climate science is creating an ecodeficit culture. Economy, Land \& Climate Insight. Retrieved from: https://elcinsight.org/western-monopoly-of-climate-science-is-creating-an-eco-deficitculture/

[6] Vuong, Q. H. (2016). Global mindset as the integration of emerging sociocultural values through mindsponge processes: A transition economy perspective. In: J. Kuada (ed.) Global Mindsets: Exploration and Perspectives (pp. 109-126). London: Routledge.

[7] Vuong, Q. H., \& Napier, N. K. (2014). Making creativity: the value of multiple filters in the innovation process. International Journal of Transitions and Innovation Systems, 3(4), 294-327. 